\title{
Brief Analysis of the Development of Sharing Economy Derivatives
}

\author{
Yan Zhu \\ School of Information Technology \& Management \\ University of International Business and Economics \\ Beijing, China
}

\begin{abstract}
Sharing economy, as a new type of economic organization, has helped to solve the surplus of idle resources, guided the economy into the New Normal and promoted the sustainable development of social economy. However, there are still problems in the industry of sharing economy, such as how to obtain considerable profits, improve consumers' mind and obtain greater consumer satisfaction and loyalty. This paper focuses on the analysis and research on the development mode of derivatives in the sharing economy, and discusses the existing growth situation of derivatives in the sharing economy by using two practical cases of Didi chuxing and Mobike. Finally, this paper concludes that the development of sharing economy derivative model is feasible and brings stable user flow to enterprises. This model still has some shortcomings that need to be improved, such as insufficient quality of derivative products and limited transformation of user consumption, which can be further studied in the future.
\end{abstract}

Keywords-Economy; Sharing economy; Derivatives; Idle resources

\section{INTRODUCTION}

The communique of the fifth plenary session of the 18th CPC central committee put forward the "sharing economy" for the first time. In September 2015, premier Li Keqiang proposed to create new businesses through sharing and cooperation and vigorously develop China's sharing economy in summer Davos Forum.

As a "new economy" and "new business" form under the Internet, the sharing economy has not developed for a long time, but it has developed rapidly. In 2014, the market scale of the sharing economy reached 15 billion dollars.

The sharing economy has gone from the hot scene of investors snatching up investment in 2016 to the cold situation of no money to reinvest in 2017. Start-ups have died one after another. In August, DING DING BIKE were declared bankrupt; In September, the office of Kuqi Bike went empty, and many users' deposits could not be found. In November, the two giants of Mobike and OFO, which share bikes, took a firm stand, but they are still looking for business breakthroughs and more ways to make money.

In 2018, Meituan acquired mobike with $35 \%$ equity and $65 \%$ cash, of which $\$ 320$ million was used as future liquidity supplement. Round A and B investors and the founding team were eliminated with $\$ 750$ million cash.

The Small Blue bike is taken over by Didi chuxing. Users can use it directly through Didi chuxing APP, and its market share gradually increases.

In terms of the capital operation of the sharing bicycle industry, there are still many challenges in the sharing economy, from the initial large capital financing, to the withdrawal of some capital investors and the occurrence of financing and acquisition. Many enterprises are still looking for the best way to operate in the market and the most appropriate profit point.

\section{LITERATURE REVIEW}

\section{A. The development of sharing economy}

The sharing economy is in a dynamic process of continuous development. There are few literatures on the sharing economy by scholars, mainly focusing on three aspects. Luo Gang (2015), based on the entrepreneurial culture of "making the world a better place", analyzed how Uber solved the difficult problem of users' taxi hailing from practical cases and founded Uber on this basis.

Xun Kong (2015) brought profound changes to the taxi and hotel industries from Uber and Airbnb, and analyzed eight industries, including express delivery industry, domestic service industry, training industry, rental industry and journalism, which will be affected by the sharing economy.

Second, to study the role of sharing economy in promoting economic growth. Peng Wensheng (2015), based on the driving force of economic growth in the 13th five-year plan, shifted from demographic dividend to institutional dividend and innovation dividend. He believed that the sharing economy, as a new type of business, is a rental economy in the Internet era and will be a new driving force for China's economic growth.

Zheng Zhilai (2016) mentioned that sharing finance, on the one hand, improves the efficiency of fund allocation for fund suppliers and realizes diversified investment demands. The social financing structure changes from debt financing to equity financing, so as to reduce the excessive debt cost of enterprises. 
platforms that share or lease certain goods or services, such as car-sharing, car-hailing or home-rental information publishing websites, which include various information sharing platforms; parliamentary second-hand trading markets (both online and offline);learning skills or talents to share.

Basic idea of sharing economy emphasizes on product "use" rather than "own", consumers are more willing to adopt "rent" rather than "buy", less spending as possible meet the production and living needs of increasingly rich, ultimately reflected in the business model is "personal(offer) — platform enterprise - individual(need)" interactive collaborative consumption patterns. In this mode, consumers fully exploit and utilize a large number of idle social resources to meet the demand in a cheaper and faster way, so as to maximize resource sharing. Therefore, collaborative consumption is also called "sharing economy".

Arises at the historic moment under the development of the Internet, sharing economy, from the germination period, rapid development, part of the fall, to re-start, its road is difficult to accurately determine the future of its development, but its business model, from a single mainstream business development to the combination of derivative products, takes one kind of feelings as driving factors, develops products of faith to consolidate the existing target consumption group.

\section{SHARING ECONOMY DERIVATIVES}

Derivatives refer to a series of services or products that can be sold by the development of the main economy, and have the brand influence of the main economy.

In combination with the concept of sharing economy, sharing economy derivatives are products derived from the sharing economy and play a role in the original brand effect. Most of the customers are loyal users.

Sharing economy has such rapid economic development, in turn, its derivatives is in early development status, and inherits the congenital conditions. In other words, by means of the Internet, sharing economy derivatives pay attention to the operation, taking the form of subsidies and other activities, building brand effect, and pay attention to operation promotion effect. Due to the large amount of user flow brought by the sharing economy platform, its future development is considerable. Based on upon, this paper, starting from Mobike and Didi chuxing company, analyzes the current development of sharing economic derivatives briefly.

\section{A. Didi chuxing - Didi mall}

Didi chuxing is a one-stop travel platform covering taxi, shuttle car, bike, express, free ride, driving agent and bus services. On September 9, 2015, it was renamed "Didi dache".

After a period of stable operation, Didi chuxing has launched the activity of credits mall, which can be exchanged for taxi coupons, traffic packages of major communication operators, food coupons, cooperative hotel coupons and so on.

According to the travel situation of users on the platform, the credits system includes the number of trips, travel expenses,
Currently, the sharing economy can be divided into three categories: information organizations and communication

The sharing economy involves the supply side, the demand Under the background of mobile Internet technology, the above participants involve in this trend and cooperate with each other, and the sharing economy develops smoothly and becomes the most innovative economic model in China. be conveniently rented, cheaply rented, safely used and stored in a standard way. 
credit rating and other behavior information, and accumulates the corresponding number of points for users, also known as didi coins.

Credit status are rated by ordinary — silver — gold black gold levels, different grades of points obtained, in order to improve user stickiness and loyalty. Users can exchange products such as Didi's own travel coupons, as well as traffic coupons or ctrip vouchers which cooperate with other enterprises, according to the number of their own coins.

Early in 2015, the consumer can see multiple commodities in Didi chuxing credits micro mall, items such as snacks, cosmetic accessories. The specific exchange model of credits is that users go to integral mall for the corresponding goods, access to exchanged code, and then to the corresponding micro mall stores to carry on the exchange, consumer protection by the mall merchants.

What is more, there are the following requirements for the merchants who are stationed in Didi credits mall: 5,000 pieces of products, the value of a single product is between 50 and 200 yuan, users can get the products with the final payment of 5-20 yuan after using the discount code, and they need to be able to deliver the products to the whole country. The exchange model is still in use, but the partners are changing.

Didi company using credit scores attracts consumers are common in traditional areas of the economy. Didi, as a sharing travel service providers, has combined the traditional marketing means, also launched credits for the activities of the goods, to a certain extent, can effectively improve user dependence of Didi, strengthening of its brand attachment, sustaining continuous use of the customer.

\section{B. Mobike - Mobike achievement hall}

Mobike is an Internet short-distance travel solution company developed by Beijing Mobike technology, which is an intelligent hardware provider for the no-pile loan model.

People can rent and return a mobike quickly via a smartphone and complete a few kilometers of city cycling at an affordable price. In the field of bike sharing, mobike has become the leading enterprise of bicycle sharing in China. It has successfully integrated into the daily life of Chinese people and changed the way people travel.

The mobike app launched the function of "worship the accomplishment pavilion", according to user's riding time, a month cycling times, sharing the worship APP page times, provided users with a certain number of coins, worship achievement including time saving coins (save riding time), the environmental protection coins (save carbon emissions), and the health coins (consuming calories), users can go to the " worship accomplishment pavilion" converted mobike coins into gifts or vouchers. This feature is considered to be one of the countermeasures against enterprise competition to ofo, put forward a way to attract users.

Users can use the currency to exchange goods in the mobike mall. These goods include two categories. The first is made by mobike company, such as custom handbags, water cups, notebooks and bike models with mobike logo. The second category is related products provided by mobike corporate partners, such as video website members, hotel vouchers, etc.

When the mobike achievement museum was just launched, users could exchange goods directly through achievement coins, but then they got off the shelf for no reason. Some people have analyzed that it may be due to the initial market investment to attract consumers. As the number of fans attracted increases, the initial investment cost reaches the upper limit, and the short-term off-line is to plan a new business development model.

Now the mobike derivatives are back on line, but they are no longer convertible currencies only by achievement coins. The newly launched mobike derivatives all require achievement currency with cash purchased, and have become a small selling department.

The most expensive item in the "mobike minishop" is the classic bag of mobike, which requires 6 mobike coins +199 yuan to be purchased. At present, there are 6 kinds of mobike physical derivatives on mobike mall online, including classic bike model key rings, theme canvas bag, thermos cups, "mofan" bags, masks and notebooks. Mobike physical objects all require achievement coins with RMB to be purchased, and the price is not cheap.

Besides their own derivatives, mobike worship accomplishment pavilion provides basic life common coupons, and the most eye-catching is the NetEase product coupons. It is believed that is also one of the worship to liquidate, worship at the accomplishment pavilion. You just need to in low achievement currency exchange commodities directly, this method will activate a large number of users for NeteEase brand and build up firm cooperation with partner.

In conclusion, mobike also need to combine product sales and advertisement marketing to promote the user consumption, except operating sharing bikes.

For Mobike company's proprietary products, more to meet the emotional routes and pay attention to brand feelings, it is beneficial to the company to expand market share, increase sales, and promote the enterprise performance in the long run. However, it is necessary to guarantee users' satisfaction with the brand, tracking source back to the good products of the enterprise, namely improving the product quality within the mall, so that the product can meet the needs of consumers. 
TABLE I. CLASSICAL DERIVATIVES IN SHARING ECONOMY

\begin{tabular}{|c|c|l|}
\hline \multicolumn{2}{|c|}{ Classical Derivatives in Sharing Economy } \\
\hline Mobike achievement hall & Form & \multicolumn{1}{c|}{ Derivatives } \\
\hline Mobike coin/cash & $\begin{array}{l}\text { Mobike homemade: bicycle model key rings, canvas bags, water cups and } \\
\text { other related bicycle accessories } \\
\text { Cooperation: NetEase Yanxuan exchange coupons, Yuni Fang coupons, } \\
\text { video membership. }\end{array}$ \\
\hline Didi Mall & Didi coin & $\begin{array}{l}\text { Didi: coupons for express, special cars and bicycles } \\
\text { Cooperation: traffic packages, food coupons, cooperative hotel coupons }\end{array}$ \\
\hline
\end{tabular}

\section{CONCLUSION}

The benign circular development of the sharing economy provides a solid foundation and a large amount of user flow for the expansion of market share of the derivatives of the sharing economy. In order to obtain a more stable business model, enterprises should continue to think about this problem and improve their business mode.

\section{A. Quality of derivatives products}

Some users reported that the derivative products provided by the platform were poor quality and had poor product experiences. Consumers pay more attention to product quality than their own consumption demands and preferences, so the sharing economic platform should start with its own derivative products to improve product quality.

\section{B. Insufficient ability to transform consumption}

Although the user flow of the sharing economy platform is large and the user group is widely distributed, it is still a problem to be solved that the product belief can be truly formed and the effective purchase amount can be formed.

This insufficient ability to transform consumption has a negative impact on the sharing of economic derivatives, which will affect the breakthrough and innovation of enterprises.

\section{Users activity}

As we know, users activity is the source of enterprise's sustainable development. Enterprises need to increase user activity and stimulate consumers' interest in consumption. Whether it is product design, incentive system, or product operation and promotion plan, enterprises need to improve users' active participation in many ways and in many ways.

\section{Industry identification}

Derivatives can effectively maintain the loyal customers sharing economy development, draw lessons from the mobike worship of the derivatives, expand the related businesses, the industry era does can be used in practice, for example, someone like Airbnb, which can develop its derivatives, such as pillows, with the love LOGO trademark; sharing cars can launch vehicle model; for other enterprises, due to the user adhesion degree of sharing economy and large user group, enterprises can promote products on this platform, which is expected to achieve good publicity and marketing effect.

\section{REFERENCES}

[1] Luo Gang. Three internal military strategies of the sharing economy triggered by Uber [J]. Zhongguancun, 2015(9):24-25. (In Chinese)

[2] Xun Kong. Eight industries in which the sharing economy will penetrate [J]. Zhongguancun, 2015(9):26-28. (In Chinese)

[3] Peng Wensheng, zhang wenlang, sun wensheng. Sharing economy is a new growth point [J]. Banker, 2015(10):64-67. (In Chinese)

[4] Zheng Zhilai. Research on sharing economy and new business model from the perspective of supply side [J]. Exploration of economic problems, 2016(6):15-20. (In Chinese)

[5] Tang Qingli. "car" class sharing economic regulation path [J]. Chinese law, 2015 (4) : 286-302. (In Chinese)

[6] Chen Jian, gong xiaoying. Difficulties and breakthroughs in sharing economic development [J]. Jiangxi social science, 2017(3):47-54. (In Chinese)

[7] Zhang Jiuqing. What is the real sharing economy -- take sharing cars for example [J]. Chinese science and technology BBS, 2018(1):0-0. (In Chinese)

[8] Ran Hua. The effect of derivatives market on economic growth [M]. China finance press, 2006. (In Chinese)

[9] Botsman Rachel, Rogers Roo. What's Mine Is Yours: The Rise of Collaborative Consumption[M]. Harper Business, 2010.

[10] Buczynski B. Sharing is Good: How to Save Money, Time and Resources through Collaborative Consumption[J]. 2013. 